\title{
Participação em redes transnacionais e a formulação de políticas locais em mudanças climáticas: 0 caso de Palmas*
}

\author{
Lia de Azevedo Almeida \\ Universidade Federal do Tocantins \\ Mônica Aparecida da Rocha Silva \\ Universidade Federal do Tocantins \\ Ronaldo Augusto Campos Pessoa \\ Universidade Federal do Tocantins
}

\begin{abstract}
Os municípios brasileiros que possuem uma política específica sobre mudanças climáticas foram ou ainda são membros da rede transnacional Local Governments for Sustainability (Iclei), sendo a cidade de Palmas-TO a primeira a instituir uma lei sobre o tema. Nesse contexto, buscou-se identificar em qual medida a participação do município na campanha Cidades pela Proteção do Clima (CPC) do Iclei influenciou a formulação e a implementação de políticas locais sobre mudanças climáticas. Foi utilizado o método qualitativo de pesquisa, por meio da análise de documentos formais e entrevistas semiestruturadas com atores da administração pública municipal e do terceiro setor. Concluiu-se que, no caso analisado, o Iclei influenciou, em parte, na ação local em mudanças climáticas, pois já havia ações da Prefeitura antes da adesão à rede; entretanto, o Iclei colaborou para o reforço da capacidade local para agir em relação à problemática.
\end{abstract}

Palavras-chave: políticas locais; mudanças climáticas; redes transnacionais; Governos Locais pela Sustentabilidade.

Participación en redes transnacionales y la formulación de políticas locales en cambios climáticos: el caso de Palmas

Los municipios brasileños que tienen una política específica acerca de cambios climáticos fueron o aún son miembros de la red transnacional Local Governments for Sustainability (Iclei), y la ciudad de Palmas, Tocantins, Brasil, fue la primera a instituir una ley acerca del tema. En ese contexto, se buscó identificar en cual medida la participación del municipio en la campaña Ciudades por la Protección del Clima (CPC) del Iclei influyó en la formulación y la implementación de políticas locales acerca de cambios climáticos. Se utilizó el método cualitativo de investigación, por medio del análisis de docu-

Artigo recebido em 23 abr. 2013 e aceito em 17 jul. 2013.

* Os autores agradecem o auxílio financeiro da Coordenação de Aperfeiçoamento de Pessoal de Nível Superior (Capes). 
mentos formales y entrevistas semi-estructuradas con actores de la administración pública municipal y del tercer sector. Se concluyó que, en el caso analizado, el Iclei ha influenciado, en parte, en la acción local en cambios climáticos, pues ya existían acciones del Ayuntamiento antes de la adhesión a la red; sin embargo, el Iclei ha contribuido al fortalecimiento de la capacidad local para actuar con relación a la problemática.

Palabras clave: políticas locales; cambio climático; redes transnacionales; Gobiernos Locales por la Sostenibilidad.

Participation in transnational networks and the formulation of local policies on climate changes: the case of Palmas

All Brazilian towns which have a specific policy on climate changes were or still are members of the transnational network Local Governments for Sustainability (Iclei), and the city of Palmas, Tocantins, Brazil, was the first to enact a law on the subject. In this context, we aimed to identify the extent to which the town's participation in the Iclei's campaign Cities for Climate Protection (CCP) influenced on the formulation and implementation of local policies on climate changes. We used the qualitative research method, by analyzing formal documents and semi-structured interviews with actors of the municipal public administration and the third sector. We found out that, in the case under analysis, Iclei has partly influenced on local action in climate changes, since there already existed actions by the City Hall prior to joining the network; however, Iclei has contributed to strengthen the local capacity to act with regard to the set of problems.

KEYwo RDs: local policy; climate change; transnational network; Local Governments for Sustainability.

\section{Introdução}

A Convenção Quadro das Nações Unidas para as Mudanças Climáticas (CQNUMC) instituiu a base para as negociações multilaterais do clima. Entretanto, atualmente há dificuldades neste âmbito de negociação e se observam poucos avanços com relação às tratativas iniciadas durante a Eco-92. Porém, tal fato não implica que a problemática da mudança do clima não esteja sendo incorporada por outros atores. Isso porque as questões ambientais globais não podem ser facilmente caracterizadas simplesmente pela dicotomia Estado/não Estado, pois nesta esfera as formas de governar são múltiplas e incluem processos e instituições, bem como redes de atores. Assim, a governança do clima requer a análise de todos os níveis, do global ao local, levando em consideração as maneiras em que processos sociais e políticos interagem entre os diferentes níveis e sistemas de governança (Bulkeley e Betsill, 2003). A própria natureza do regime intergovernamental para as mudanças climáticas cria mecanismos e oportunidades que facilitam a governança transnacional. Um exemplo é a adoção de três mecanismos flexíveis (Implementação Conjunta, Mecanismo de Desenvolvimento Limpo e o Comércio de Emissões) no âmbito do Protocolo de Kyoto, que proporcionou a atuação de atores transnacionais interessados em se envolver nos mecanismos (Andonova, Betsill e Bulkeley, 2007). 
Entre os diversos atores que participam da governança transnacional do clima, os governos subnacionais, especialmente os municípios, de vários países, vêm a algum tempo tomando suas próprias ações no que concerne à questão climática, antecipando-se às normas nacionais ou internacionais (Lankao, 2007a). Nos países da América Latina, esse fenômeno foi possibilitado em grande medida pelo processo de descentralização decorrente da reforma do Estado, que aumentou a autoridade e a jurisdição dos governos locais nas últimas décadas como forma de melhorar a efetividade de várias políticas públicas (Evans et al., 2005; Satterthwaite et al., 2007).

Em relação à gestão municipal, os governos locais dispõem de diversos mecanismos institucionais para enfrentar o processo de degradação socioambiental (Ferreira, 1999; Hogan, 2001; Jacobi, 2006). Entretanto, segundo Ferreira (2003), vários governos ainda não estão suficientemente equipados para enfrentar os problemas ambientais globais, principalmente no que diz respeito às mudanças climáticas.

No intuito de compensar essa deficiência, os governos locais vêm procurando agir em conjunto, por meio de redes transnacionais de municípios ou Transnational Municipal Networks (TMNs). Enquanto organização, as redes atuam representando os interesses dos governos subnacionais nas negociações internacionais do clima e trabalham a fim de criar capacidade local para que o município possa implantar medidas e políticas visando à proteção climática (Bulkeley e Betsill, 2003).

O Brasil, apesar de ter assumido uma postura ativa nas negociações internacionais do clima, só recentemente aprovou sua Política Nacional de Controle das Mudanças Climáticas, e não assumiu compromissos obrigatórios de redução de emissões de gases geradores do efeito estufa (GEE) na arena internacional. Por outro lado, há algum tempo já vêm sendo registradas iniciativas de governos subnacionais brasileiros, no estabelecimento de políticas e medidas visando à proteção do clima.

Em 2001, oito cidades brasileiras faziam parte da campanha Cidades pela Proteção do Clima (CCP) promovida pela rede transnacional Local Governments for Sustainability (ICLEI). Em 2003, a cidade de Palmas, participante da Campanha CCP, já havia instituído sua Política Municipal de Mudanças Climáticas, tornando-se assim a primeira cidade brasileira a adotar tal medida, seguida por São Paulo (2009) e Rio de Janeiro (2011). É interessante observar que em todas as cidades brasileiras que, atualmente, possuem uma Política Municipal de Mudanças Climáticas, foram ou ainda são membros da rede Iclei e participaram da Campanha CCP, como Palmas, São Paulo e Rio de Janeiro.

Nessa perspectiva, o presente artigo busca compreender a relação entre participação em redes transnacionais e a influência desse engajamento na formulação de políticas públicas municipais. Assim, este trabalho tem como objetivo averiguar em que medida o processo de aprendizagem e construção de capacidades, que estão presentes nos discursos das redes, como o Iclei, pode ter influenciado a formulação e a implementação de políticas locais em mudanças climáticas no município de Palmas. 


\section{Metodologia}

Optou-se pela estratégia de estudo de caso único, devido à especificidade do objeto analisado em relação às seguintes características: o porte municipal (uma cidade média), as características de constituição do município (a mais nova capital do país) e por ser o primeiro município brasileiro a instituir uma lei municipal específica sobre mudanças climáticas. Seguiu-se uma abordagem qualitativa, por meio da realização de pesquisa bibliográfica e documental e entrevistas individuais semiestruturadas. Quanto aos documentos analisados, os mesmos compuseram-se de leis municipais, do texto do Projeto de Sequestro de Carbono de Urbano de Palmas (PSCUP) e materiais de divulgação da Campanha CCP pelo Iclei (impressos e digitais), além de informações veiculadas pela mídia. A análise dos documentos buscou identificar como se deu a participação de Palmas na Campanha CCP, a atuação da prefeitura na temática ambiental e a tramitação da Lei municipal no 1.182 que instituiu a Política Municipal de Mudanças Climáticas.

A análise dos documentos permitiu estimar que a adesão de Palmas ao Iclei ocorreu entre o final de 2002 e início de 2003, e finalizou em fins de 2004. Desse modo, buscou-se entrevistar atores de diversos setores envolvidos de alguma forma com a participação do município no Iclei. Logo, optou-se por entrevistar tanto os atores contemporâneos à participação da cidade no Iclei, quanto os participantes da última gestão municipal (2009-12) em que o município não mais participava da rede. Procurou-se, com isso, dar voz aos atores que puderam acompanhar os efeitos "pós-participação no Iclei", pois as falas desses entrevistados poderiam revelar peculiaridades importantes e diversas daquelas propiciadas pelos atores que estavam envolvidos de alguma forma na participação do município na rede, e, assim, contribuir para a compreensão dos motivos que levaram ao desligamento da participação no Iclei, além de permitir o estabelecimento de comparações das informações obtidas nos depoimentos.

Assim, foram entrevistados: o prefeito (gestão 2009-12); o secretário de Meio Ambiente e o diretor de Meio Ambiente da Secretaria Municipal de Meio Ambiente e Serviços Públicos (Smasp). Quanto aos atores envolvidos na gestão 2001-04 - quando Palmas aderiu ao Iclei —, foram entrevistados: gerente de Projetos e gerente de Meio Ambiente da Agência Municipal de Meio Ambiente e Turismo (Amatur). Além disso, como representante do terceiro setor, foi entrevistado o ex-presidente do Instituto Ecológica.

Como procedimento de análise dos dados foram realizadas a interpretação e a codificação de acordo com os objetivos específicos do trabalho, os quais foram sintetizados em cinco unidades de análise: a) a motivação do município para a participação na campanha CCP do Iclei; b) a participação do Iclei no desenho institucional da Lei de Mudanças Climáticas; c) a atuação do município na rede; d) a capacitação e a assessoria técnica proporcionada pela rede e a criação de capacidade local; e e) aprendizado em rede e troca de experiências. 


\section{Municípios, mudanças climáticas e redes transnacionais}

A discussão sobre políticas municipais de mudanças climáticas é muito recente no Brasil, e de certa forma no mundo, pois as resoluções nesta esfera ficaram restritas durante muito tempo às negociações entre Estados-nação e à adoção de protocolos e tratados que não envolviam este nível de governo.

Entretanto, as questões ambientais globais não podem ser facilmente caracterizadas simplesmente pela dicotomia Estado/não Estado, pois nessa esfera as formas de governar são múltiplas e incluem processos e instituições, bem como redes de atores. Assim, a governança do clima requer a análise de todos os níveis, do global ao local, levando em consideração as maneiras em que processos sociais e políticos interagem entre os diferentes níveis e sistemas de governança (Bulkeley e Betsill, 2003).

O campo das mudanças climáticas é um terreno propício para o surgimento da governança transnacional, uma vez que é caracterizado por um elevado grau de complexidade e necessidade de coordenação de políticas vertical e horizontalmente (Andonova et al., 2007). A governança em mudanças climáticas envolve vários setores, muitas vezes com interesses e papéis divergentes. Isso faz com que a questão climática seja tratada de forma separada, dividida entre os diversos assuntos relacionados. Entretanto, essa estrutura oferece oportunidades para a cooperação transfronteiriça entre os atores que atuam em aspectos semelhantes do problema. Além disso, a própria natureza do regime intergovernamental para as mudanças climáticas cria mecanismos e oportunidades que facilitam a governança transnacional. Um exemplo disso é a adoção de três mecanismos flexíveis (Implementação Conjunta, Mecanismo de Desenvolvimento Limpo e Comércio de Emissões) no âmbito do Protocolo de Kyoto, que possibilitou a atuação de atores transnacionais interessados em se envolver nos mecanismos (Andonova et al., 2007).

Entre os diversos atores que participam da governança transnacional do clima, os governos subnacionais, especialmente os municípios, de vários países, vêm a algum tempo tomando suas próprias ações no que concerne à questão climática, antecipando-se às normas nacionais ou internacionais (Lankao, 2007a). Nos países da América Latina esse fenômeno foi possibilitado em grande medida pelo processo de Reforma do Estado (Evans et al., 2005; Satterthwaite et al., 2007), que, além de aumentar a jurisdição dos municípios, possibilitou a abertura de canais de participação, fomentando dinâmicas inovadoras informais e flexíveis e ambiente favorável à constituição de parcerias (Loiola e Moura, 1997), como é o caso das redes.

Assim, diante de uma crise fiscal do Estado, aliada a uma crise do modelo de administração pública burocrática e a uma crise de governança (Pereira, 1999; Abrucio, 1996), era necessária uma reforma rumo a "um Estado dotado de maior flexibilidade, que pudesse descentralizar funções e transferir responsabilidades alargando ao mesmo tempo o universo dos atores participantes, sem, contudo, abrir mão dos instrumentos de controle e supervisão" (Diniz, 1995:392).

Nesse sentido, houve uma redefinição e rearticulação das relações entre Estado e sociedade, e a ideia de "governo" dá lugar ao conceito mais amplo de "governança", incluindo-se 
aí "não apenas os mecanismos tradicionais de agregação e articulação de interesses, tais como partidos políticos e grupos de pressão, como também redes sociais informais" (Santos, 1997).

No caso brasileiro, a Constituição Federal de 1988 elevou os municípios à categoria de unidade federativa e estabeleceu a "repartição de competências e a previsão do direito ao meio ambiente" (Scardua e Bursztyn, 2003:302).

Quanto à questão do clima, o entendimento de que o município é um agente fundamental nas medidas de mitigação e adaptação às mudanças climáticas baseia-se na suposição de que os governos locais são mais flexíveis e mais responsáveis perante os seus cidadãos do que outros níveis de governança. Neste nível, devido a sua menor dimensão, supõe-se que as decisões podem ser tomadas mais rapidamente do que em nível nacional, possuindo mais flexibilidade e agilidade nas respostas, também motivada pelo contato diário com grupos de interesse, tais como sociedade civil, organizações de base comunitária e grupos ambientalistas, os quais exercem pressão e controle diariamente (Puppim de Oliveira, 2009).

Segundo Castels (1998), evidências empíricas parecem demonstrar que a proximidade do governo e dos cidadãos no âmbito local permite um controle social mais transparente e reforça as oportunidades de participação política e, no limite, de relegitimação do Estado. Além da possibilidade de um maior controle social, há uma vasta literatura que compreende como fundamental a ação local em mudanças climáticas. Robinson e Gore (2005) abordam a relação entre cidades e as mudanças climáticas baseada em uma complexa balança entre vulnerabilidade e responsabilidade.

A vulnerabilidade reside no fato de que as cidades estão suscetíveis a uma vasta gama de impactos de mudanças climáticas. Por outro lado, a autoridade local possui uma responsabilidade legal que proporciona oportunidades de influenciar muitas atividades que contribuem para as mudanças climáticas e respondem em termos de políticas de mitigação e adaptação (Robinson e Gore, 2005; Bulkeley e Betsill, 2003).

Diversos fatores explicam a vulnerabilidade das cidades aos efeitos das mudanças climáticas. A explicação mais simples reside no fato de que grande parte das atividades humanas que levam ao aquecimento global e contribuem para as transformações ambientais globais, em geral, acontece em nível local (Wilbanks e Kates, 1999). É nas cidades que ocorrem atividades altamente intensivas em consumo de energia, o que as tornam grandes fontes emissoras de gases geradores de efeito estufa (Lankao, 2007a, 2007b). Nesse sentido, destacam-se os grandes centros urbanos que agregam um elevado número de indústrias, ampla infraestrutura e contingente populacional (Wilbanks et al., 2007; Satterthwaite et al., 2007; Lankao, 2007b; Satterthwaite et al., 2008). Assim, como expõem Martins e Ferreira (2011:614), “(...) é praticamente impossível conceber qualquer resposta mitigadora ou ação adaptativa sem enfrentar a discussão sobre cidades, urbanização e governança local".

A responsabilidade identificada por Robson e Gore (2005) reside no fato de que geralmente o município tem responsabilidade legal para controlar áreas e setores estratégicos que podem influenciar muitas atividades que são tanto fontes críticas de emissões de GEE, quanto instrumentos-chave na redução dos riscos climáticos urbanos, tais como regulamentação do uso do solo, zoneamento, defesa civil, entre outros (Satterthwaite et al., 2007; Bulkeley et al., 2009). 
Por outro lado, apesar do reconhecimento da importância da gestão do clima pelos municípios, alguns autores chamam a atenção para a necessidade de articulações com outras instâncias de governança para que possam estabelecer medidas efetivas, tanto de mitigação quanto de adaptação (Ribeiro, 2008; Satterthwaite et al., 2007).

Segundo Martins e Ferreira (2010), ao analisar estudos de casos que envolviam 38 cidades em todo o mundo, concluíram que a participação em redes transnacionais de municípios aparece como um arranjo de governança que impulsiona a ação local em mudanças climáticas.

As redes transnacionais de municípios, ou TMNs, como são denominadas pelos autores internacionais (fazendo referência à sigla originária do inglês Transnational Municipal Networks), tiveram seu surgimento influenciado por alguns acontecimentos específicos e são comumente vistas como um resultado concreto da Cúpula do Rio em 1992 (Betsill e Bulkeley, 2006). O aumento da existência deste tipo de redes tem sido marcante nos últimos anos. De acordo com Keiner e Kim (2006), entre os anos de 1982 e 2004, o número de redes de cidades voltadas para a sustentabilidade aumentou de oito para 49. De acordo com Kern e Alber (2008:14, tradução nossa), os objetivos das redes transnacionais de cidades "incluem a transferência de melhores práticas, a aprendizagem entre os seus membros em âmbito doméstico e no exterior, e a representação dos interesses dos seus membros no âmbito nacional, europeu e internacional do sistema multinível".

Assim, para que o município possa gerir uma questão tão complexa, como a climática, as redes transnacionais apareceriam como uma ferramenta de governança que o município poderia se utilizar para conseguir agir localmente sobre um problema global. Nesse sentido, tais redes operam como interlocutoras entre o governo local e o meio internacional, procurando advogar perante os governos nacionais, as organizações regionais e os diversos organismos multilaterais e instituições que fazem parte do regime internacional de mudanças climáticas, objetivando reforçar o papel dos governos locais na temática. Além do papel de advocacy, objetivam igualmente reforçar a capacidade do governo local em lidar com o tema, a partir do intercâmbio e da disseminação de boas práticas que caracterizam o trabalho em rede.

\section{O Iclei e a campanha CCP}

O Iclei é uma das maiores redes transnacionais que atuam na temática ambiental (Betsill e Bulkeley, 2006). A organização foi fundada em 1990, pela International Union of Local Authorities (Uila) e o United Nations Environment Programme (Unep), para representar os governos locais internacionalmente quanto à questão ambiental (Betsill e Bulkeley, 2004).

A organização se autodefine como um movimento e como uma agência de desenvolvimento sustentável para os governos locais. Enquanto movimento, a organização "desenvolve e gerencia diversas campanhas e programas que abordam questões de sustentabilidade local (...) fazendo a ligação entre a ação local e as metas e objetivos de acordos internacionais" (Iclei, 2013). Como agência de desenvolvimento sustentável para governos locais, o Iclei "for- 
nece informações, providencia treinamentos, organiza conferências, facilita o intercâmbio entre cidades e a constituição de redes, executa pesquisas e projetos piloto, além de prestar serviços técnicos e de consultoria" (Iclei, 2013).

Atualmente, são membros do Iclei mais de 1.100 municípios e associações em todo o mundo (Iclei, 2013). De acordo com a organização: "Na América Latina, 23 governos locais são membros ativos; e mais de 100 assumiram o compromisso de executar o desenvolvimento sustentável através das campanhas e programas do Iclei-Lacs" (Iclei, 2013). No Brasil, são 26 membros, e apenas três não são governos locais, sendo eles o estado de São Paulo, o estado de Minas Gerais e o Instituto de Pesquisa, Administração e Planejamento de São José dos Campos (Ipplan) (Iclei, 2013).

Além das campanhas que visam à realização de políticas e medidas de adaptação e mitigação, o Iclei tem tido bastante destaque em suas ações de advocacy internacional, defendendo a importância dos governos locais nas discussões empreendidas no âmbito do regime internacional do clima.

Quanto às campanhas desenvolvidas, destaca-se a CCP. A campanha foi inspirada no projeto anterior Redução de $\mathrm{CO}_{2}$ nas Cidades, que reuniu cidades americanas, canadenses e europeias para desenvolver uma estrutura de planejamento municipal para redução de GEE e gestão estratégica de energia (Betsill e Bulkeley, 2004). Em 1993, e como uma continuidade desta iniciativa e reflexo da adoção pelos Estados-nação da Convenção Quadro das Nações Unidas Sobre Mudança do Clima durante a Eco-92 e da primeira Cúpula de Líderes Municipais sobre Mudanças Climáticas, teve início a campanha CCP, em Nova York (Iclei, 2013). A ideia inicial da campanha residia na união das autoridades locais para trabalharem juntamente com os governos nacionais e com agências internacionais para desenvolver e programar estratégias para reduzir as emissões de gases de efeito estufa e para proteger a capacidade do ambiente biológico para remover o $\mathrm{CO}_{2}$ (Iclei, 1993a:1 apud Lindseth, 2004). No ano de 2001, faziam parte da campanha 549 cidades em todo o mundo, cujas emissões juntas representavam 8\% das emissões globais (Bulkeley e Betsill, 2003).

O IcleI lançou campanhas nacionais, a partir do ano de 2002, em diversos países e campanhas regionais foram lançadas na Europa, Ásia e América Latina (Bulkeley e Betsill, 2004). Na América Latina, a campanha CCP iniciou-se em 1998, no México; a partir de 2001, estendeu-se para a América do Sul, com apoio financeiro da Agência Canadense de Desenvolvimento Internacional (Cida). No Brasil, participaram da campanha CCP as seguintes cidades: Belo Horizonte, Betim, Goiânia, Palmas, Porto Alegre, Rio de Janeiro, São Paulo e Volta Redonda (Iclei, 2013).

Entre os objetivos estabelecidos para a campanha estavam: (1) o reforço dos compromissos locais para reduzir as emissões urbanas de gases de efeito estufa; (2) a divulgação de ferramentas de gestão e planejamento para facilitar o desenvolvimento da relação custobenefício das políticas de redução de $\mathrm{CO}_{2}$; (3) a pesquisa e desenvolvimento de melhores práticas, e municípios-modelo, os quais deveriam servir de referência; e (4) o reforço dos laços nacionais e internacionais para que as ações em nível municipal estejam incluídas nos planos de ação nacional e nas deliberações internacionais (Iclei, 1993b apud Lindseth, 2004). 
Uma vez que adere à campanha, o governo local deve passar por cinco etapas. As etapas ou marcos compõem-se de uma metodologia a fim de auxiliar os governos locais a entender como as decisões municipais afetam o uso da energia, e como reduções no consumo de energia podem mitigar as mudanças climáticas melhorando a qualidade de vida (Lindseth, 2004). As cinco etapas compreendem: a construção de um inventário de padrões de emissões; a adoção de metas de redução de emissões; o desenvolvimento de um plano de ação local; a execução de políticas e medidas; e o monitoramento dos resultados (Betsill e Bulkeley, 2004).

Para concluir as cinco etapas, as cidades recebem assistência técnica e treinamento por parte do Iclei, na forma de workshops, financiamento para realizar a análise de emissões e um software especialmente concebido para possibilitar às cidades o cálculo de suas emissões passadas e atuais, bem como a avaliação de opções para reduzir as emissões e o monitoramento dos efeitos das medidas de redução em termos de economia de custos e de emissões de GEE (Betsill, 2001).

A campanha CCP tem como premissa a suposição de que a atuação de qualquer governo local para reduzir as emissões de gases de efeito estufa pode ser relativamente modesta; entretanto, o trabalho em conjunto com outros governos locais pode resultar em uma contribuição significativa nos esforços de mitigação das mudanças climáticas (Betsill e Bulkeley, 2004). A campanha baseia-se na ideia de que o envolvimento dos governos locais na problemática da mudança do clima se faz necessário, uma vez que este é o nível mais próximo do povo.

De acordo com Betsill e Bulkeley (2004), o programa baseia-se na suposição de que o aumento de informações sobre o problema e as possíveis soluções possibilitam a criação de uma mudança política de maneira relativamente simples. Por isso, a ênfase no aumento da capacidade de monitoração e previsão de emissões (através do software para esta finalidade) e na difusão de boas práticas. O reforço da capacidade local se daria por meio de um processo cíclico, cuja primeira fase seria a adesão à campanha, seguido pela informação sobre as emissões locais e disseminação de boas práticas, o que levaria a um conhecimento local das causas das mudanças climáticas, que consequentemente estimularia a implementação de novas políticas locais (Betsill e Bulkeley, 2004).

\section{0 município de Palmas: projetos, Política de Mudanças Climáticas e a campanha CCP do Iclei}

No Brasil, têm sido registradas algumas iniciativas de governos subnacionais com relação à proteção do clima, sendo desenvolvidas ou já em andamento. Porém, quando se trata de leis municipais, apenas uma pequena parcela de municípios pode ser mencionada. Conforme pesquisa realizada, em 2009, pela Confederação Nacional dos Municípios (CNM), apenas 197 municípios (3,9\% do total) possuem projeto de lei, decreto ou lei específica para tratar das mudanças climáticas, destes apenas 112 municípios (57\%) possuem uma lei ou decreto regulamentado e, destes, apenas 60 (54\%) apresentam uma meta específica de redução de gases de efeito estufa (CNM, 2009). 
Esses dados revelam um aspecto interessante, uma vez que a cidade de Palmas não possui grandes ameaças ambientais como São Paulo e Rio de Janeiro, porém foi a pioneira na criação de uma lei sobre mudanças climáticas. Outra peculiaridade do município são os grandes vazios urbanos, que desde sua constituição contribuem para que a cidade possua o mais elevado custo per capita de urbanização do país, estimado no ano de 2005 em R \$ 216,79 (Bazolli, 2009). Em 2002, a cidade apresentava um elevado índice de área verde por habitante, aproximadamente $280 \mathrm{~m}^{2}$, decorrente em parte das características de arborização previstas em seu plano diretor, e também pelos grandes vazios urbanos característicos do seu processo de ocupação (PSCUP, 2002). Neste caso, a existência de grandes áreas verdes tornava ainda mais custosa a manutenção dessas áreas e a gestão urbana do município.

A gestão ambiental do município atualmente é de responsabilidade da Secretaria de Meio Ambiente e Serviços Públicos, porém, na época da adesão de Palmas à Campanha CCP do Iclei, tal atribuição competia à Amatur. A agência foi criada em junho de 2001, como órgão executivo da Política Ambiental do Município de Palmas instituído pela Lei no 1.011, de 4 de junho de 2001. A referida lei criou o Sistema Municipal de Meio Ambiente (Simma), do qual faziam parte, além da Amatur, o Conselho Municipal de Meio Ambiente (CMMA) e organizações da sociedade civil que tivessem como objetivo a preservação e/ou a conservação do meio ambiente.

A Amatur era o órgão responsável pela coordenação, controle e execução da Política Municipal de Meio Ambiente, na gestão 2001-04. Entre suas atribuições estava a participação no planejamento das políticas públicas do município; a coordenação das ações dos órgãos integrantes do Simma; o exercício do controle, monitoramento e avaliação dos recursos naturais; podendo articular-se com organismos federais, estaduais, municipais e organizações não governamentais (ONGs) para a execução coordenada e a obtenção de financiamentos para a implantação de programas. Além disso, caberia à Amatur coordenar a gestão do Fundo Municipal do Meio Ambiente (FMMA), regulamentado pelo Decreto-lei no 244 .

\section{O projeto de sequestro de carbono e a participação no Iclei}

Entre os projetos desenvolvidos no âmbito da Política Municipal de Meio Ambiente, destacase o Projeto de Sequestro de Carbono Urbano (PSCUP), que à época teve destaque pela imprensa nacional devido a seu pioneirismo, por ser o primeiro projeto de sequestro de carbono em área urbana e em área pública, e isto colaborou sobremaneira para que Palmas pudesse ser incluída entre as oito cidades até então selecionadas para participar da campanha CCP.

O Projeto de Sequestro de Carbono Urbano de Palmas foi elaborado em junho de 2002 e contou com o apoio de diversas instituições, dentre elas o Ministério do Meio Ambiente (MMA) e o Banco Mundial (Bird). O principal objetivo era a absorção de dióxido de carbono $\left(\mathrm{CO}_{2}\right)$ da atmosfera, a partir da adoção do Mecanismo de Desenvolvimento Limpo (MDL), e a comercialização dos créditos de carbono por meio da prática do conceito do "carbono social" (PSCUP, 2002). O Projeto abrangeria as áreas pertencentes ao poder público municipal, que 
se encontrava em avançado estado de degradação devido principalmente ao desmatamento ilegal decorrente da pressão para a implantação da cidade. Tais áreas seriam transformadas em unidades de conservação municipais (UCs) durante o processo de implementação do projeto (PSCUP, 2002).

No próprio texto do projeto estava estabelecido que os recursos oriundos da venda de créditos de carbono via Mecanismo de Desenvolvimento Limpo (MDL) seriam investidos em quatro áreas: a) projetos sociais, que iam desde a educação ambiental, até ações envolvendo a promoção do turismo; b) redução das emissões de gases de efeito estufa, por meio da implantação de parques e jardins e conservação e regeneração de áreas verdes degradadas; c) fortalecimento do sistema de monitoramento ambiental; d) capacitação da comunidade para projetos de geração de renda (PSCUP, 2002).

A participação de Palmas na Campanha CCP do Iclei esteve fortemente vinculada ao projeto de sequestro de carbono que já havia sido elaborado, por iniciativa da prefeitura. Isso ficou bastante claro nas falas da quase totalidade dos entrevistados. Neste sentido, de acordo com o então presidente da extinta Amatur: “(...) como o projeto de sequestro de carbono era muito atraente, o Iclei abriu uma exceção e incluiu Palmas e passaram a ser dez cidades". O gerente de projetos da extinta Amatur segue na mesma direção: “(...) para que nos tornássemos digamos... elegíveis na campanha, o projeto de sequestro de carbono foi muito preponderante". Essa relação também fica clara com as notícias que foram veiculadas nos meios de comunicação da época, que davam mais destaque ao projeto de sequestro de carbono e ao seu caráter inovador e pioneiro, enquanto a participação no Iclei aparecia como uma forma de reconhecimento da importância do projeto.

Isso nos permite refletir que a ascensão a esse tipo de rede, ou pelo menos às suas campanhas e/ou projetos principais, já requer um engajamento prévio relevante da administração pública nas questões climáticas. O que nos faz questionar sobre qual é o papel que a rede desempenha na motivação das cidades para agir em relação às mudanças climáticas, ou seja, até que ponto a rede trabalharia mais como uma espécie de "catalizadora" de bons casos, ou de casos em potencial, do que como uma "motivadora" para que esses casos existam.

Ao mesmo tempo que o projeto de sequestro de carbono atraiu a atenção do Iclei e possibilitou a inclusão de Palmas na campanha CCP, a prefeitura via nesse engajamento uma possibilidade de implementar o projeto inovador. Isso porque um projeto de mitigação dos gases causadores do efeito estufa via MDL, como era o caso, é um tipo de cooperação transnacional que envolve um país financiador e um país-sede (PSCUP, 2002).

Assim, além de conferir legitimidade ao projeto, a participação no Iclei era entendida como uma forma de divulgá-lo e atrair a atenção de instituições financiadoras de outros países, uma vez que o Iclei, por meio de sua expertise na área, poderia orientar a prefeitura sobre as fontes de obtenção de recursos financeiros. Tal fato fica evidente na fala do então gerente de meio ambiente da extinta Amatur: “(...) o Iclei é essa mola propulsora, ele vai buscar o recurso. A organização em si não tem o recurso, mas ela vai buscar onde existe".

Considerando o porte municipal e a baixa capacidade de arrecadação do município, é compreensível que o fator "recursos financeiros" fosse a preocupação principal dos gestores 
da época. O projeto de sequestro de carbono, nesse caso, foi utilizado como forma de captação desses recursos. O foco demasiado na busca de recursos em detrimento de capacitação técnica ou outras possibilidades proporcionadas pelas redes transnacionais pode evidenciar um diferencial da atuação de cidades médias neste tipo de rede. Contrariamente ao evidenciado em Palmas, Setzer (2009), abordando o caso da cidade e do estado de São Paulo, revelou que nenhum dos seus entrevistados considerou o fator recursos como um fator que influenciaria as políticas locais e estaduais sobre as mudanças climáticas, uma vez que São Paulo é o estado mais rico do país e sua secretaria de meio ambiente possui mais autonomia que outras. Na esfera municipal, os entrevistados reportaram que o principal obstáculo está mais nas dificuldades institucionais de reinvestir recursos do que na própria falta de recursos (Setzer, 2009).

\section{A lei de mudanças climáticas e a influência da participação do Iclei}

O projeto de sequestro de carbono, a criação da Lei Municipal de Mudanças Climáticas — que já era prevista no texto do projeto - e a participação na campanha CCP do Iclei aparecem nas falas dos entrevistados como ações bastante interligadas, chegando-se ao ponto de até mesmo confundi-las. As mesmas são entendidas como estratégias de um projeto mais amplo, cujo ponto focal era o Projeto de Sequestro de Carbono. Ao se referir à lei de mudanças climáticas, o ex-presidente da Amatur afirmou que a mesma era vista como um instrumento para: “(...) vender, no bom sentido, um projeto de sequestro de carbono".

Isso fica bastante claro ao se analisar o texto da lei, o qual se restringe à regulação das ações do município com relação a projetos nas áreas florestal e energética, autorizando a Amatur a negociar e comercializar os créditos de carbono fixados nas áreas verdes especiais e contratar assessoria técnica para orientação das diretrizes dos projetos na área de mudanças climáticas (Palmas, 2003).

Dessa forma, a política possui um caráter regulatório e a própria criação da lei já estava prevista no texto do Projeto de Sequestro de Carbono como uma das ações a serem desenvolvidas, pois se fazia necessário regulamentar as ações do município em projetos desta natureza. O projeto de lei foi proposto pelo Executivo em novembro de 2002 e sancionado em maio de 2003, o que nos leva a crer que houve relativa facilidade na instância legislativa. Tal fato pode ser explicado pelo caráter regulatório da lei, a qual, diferentemente das políticas municipais de São Paulo e Rio de Janeiro, não fixava metas de redução de emissão de $\mathrm{CO}_{2}$.

A motivação para a criação da lei de mudanças climáticas partiu da Prefeitura de Palmas, antes mesmo da adesão à rede. Em relação à participação do Iclei na formulação da lei, a maioria dos entrevistados não a destacou como relevante, apenas o gerente de Meio Ambiente da extinta Amatur ressaltou que a participação do Iclei foi a de oferecer orientação quanto à elaboração da lei; entretanto, essa orientação foi recebida também de diversos outros atores. Ainda segundo o referido entrevistado: "o Iclei nos orientou nisso também, mas em cada evento que a gente ia, em cada lugar que a agente ia apresentar o projeto, sugestões eram dadas a bem que fosse mais fácil para um organismo internacional 'comprar' o nosso projeto". Os 
demais entrevistados não ressaltaram a participação do Iclei como relevante na formulação da lei, ressaltando sempre que a iniciativa partiu da prefeitura.

Assim, em Palmas, ao contrário de São Paulo, o engajamento do Iclei não ocorreu formalmente para o desenho institucional da lei. Segundo Biderman (2011:132), no caso da cidade de São Paulo, "o engajamento do Iclei deu-se em diferentes momentos e teve início bem antes da formulação da política de clima". Os depoimentos colhidos em sua pesquisa permitiram identificar a existência de uma forte parceria da prefeitura, por meio da Secretaria do Verde e Meio Ambiente, com o Iclei para a execução de diferentes iniciativas que tornaram possível a elaboração da Lei da Política de Mudança do Clima de São Paulo, sua implementação e a criação do Comitê Municipal de Mudança do Clima e Ecoeconomia (Biderman, 2011).

\section{Assessoria técnica e reforço da capacidade local}

A possibilidade de reforço da capacidade local por meio da assessoria técnica proporcionada pela participação na Campanha CCP foi fundamental para que a cidade estabelecesse políticas e medidas relacionadas à redução de emissões de GEE, o que ficou bastante claro em alguns depoimentos. A ex-gerente de meio ambiente da extinta Amatur, ao se referir ao inventário de emissões, relata que “(...) esse diagnóstico (...) foi um espetáculo na época, porque ele apontou realmente em que nós deveríamos atuar. Então, a partir daí outras ações dentro da secretaria começaram a surgir, e outras que já existiam foram fortalecidas".

A referida entrevistada destacou, ainda, que a realização do inventário de emissões de GEE colaborou para o reforço de programas que já existiam antes da realização do mesmo, como é o caso do programa: "Aqui o Desperdício não é Nada Natural”, que visava à conscientização dos funcionários da administração pública municipal quanto ao desperdício de água, energia e papel. Segundo a referida entrevistada, o programa já existia antes da participação de Palmas no Iclei, mas foi reforçado após a realização do inventário de emissões de GEE, pois se viu que era uma ação estratégica para a consecução da meta de redução de $20 \%$ das emissões de GEE, estabelecida pelo município no âmbito da campanha CCP.

Desta forma, em Palmas, o software e a assessoria técnica prestada pelo Iclei foram fundamentais para a elaboração de um inventário de emissões, o que não ocorreu no caso dos municípios de São Paulo e Rio de Janeiro, que estabeleceram parcerias com universidades e centros de pesquisa para a elaboração de seus inventários de emissões, não dependendo fundamentalmente de ferramentas proporcionadas pelo Iclei (Biderman, 2011; Puppim de Oliveira, 2009). Estudo realizado por Betsill e Bulkeley (2004) revelou comportamentos semelhantes aos de São Paulo e Rio de Janeiro, quando analisaram seis cidades no Reino Unido, Estados Unidos e Austrália. Nesses casos, a adesão à campanha CCP não foi preponderante para a confecção de inventários de emissões. Em quatro das seis cidades analisadas já havia estudos sobre a natureza das emissões de gases de efeito estufa antes mesmo da adesão ao CCP. Em Newcastle e Leicester, no Reino Unido, havia inventários exaustivos sobre o uso de 
energia e as emissões de GEE, bem como várias estratégias de conservação de energia e de incremento do uso de fontes de energia alternativa tinham sido desenvolvidas previamente à participação na campanha (Betsill e Bulkeley, 2004).

Em Palmas, ao contrário dos casos mencionados, nenhuma parceria foi feita com instituições de pesquisas ou com universidades para realização de estudos e diagnósticos de emissões de GEE, e, neste caso, o fornecimento de assistência técnica pelo Iclei teve um impacto muito maior e foi muito mais decisivo para a elaboração do inventário.

Após a realização do inventário de emissões, a terceira etapa da campanha era a realização de um Plano de Ação com o estabelecimento de uma meta de redução de GEE e o estabelecimento de políticas e medidas para se alcançar esse objetivo. O município apresentou seu plano de ação durante o V workshop da campanha CCP, em outubro de 2004, logo após as eleições municipais.

\section{A extinção da Amatur e o fim da associação de Palmas ao Iclei}

No início da gestão 2005-08, a organização e a estrutura administrativa do Poder Executivo municipal foram alteradas mediante a Lei $\mathrm{n}^{-} \mathbf{1 . 3 6 5}$, de março de 2005 . Com a nova estrutura, a Amatur foi extinta e a gestão ambiental passou a ser de responsabilidade da Secretaria de Meio Ambiente e Turismo, órgão da administração direta. Quanto às atribuições da recémcriada secretaria, não se faz menção no texto da referida lei quanto à possibilidade de comercialização de créditos de carbono via MDL. Na nova gestão, o projeto de sequestro de carbono não chegou a ser implementado, Palmas se desligou do Iclei e, consequentemente, da participação na campanha CCP. Dessa forma, o município realizou apenas três etapas das cinco que compõem a campanha CCP. Porém, o não cumprimento das cinco etapas é um comportamento bastante comum entre as demais cidades participantes da campanha. Lindseth (2004), ao analisar a pesquisa realizada pelo Iclei em 1997 com as cidades participantes da campanha CCP, destaca que, na maioria das vezes, após analisar minuciosamente o uso de energia e as emissões locais, as cidades definem metas e cronogramas, porém, dos 174 governos locais pesquisados, apenas 31 completaram as cinco etapas propostas pela campanha. Os motivos para o não cumprimento são variados e dependem de cada caso.

Ao ser indagado se tinha conhecimento das ações desenvolvidas no âmbito da participação na CCP, o então prefeito, que cumpria seu segundo mandato (2009-12), afirmou que: "Conhecimento nós tivemos, o que eu achei estranho é que nada ficou registrado na Prefeitura (...) mas não herdamos isso de forma materializada". O então prefeito alegou ter conhecimento do Projeto de Sequestro de Carbono apenas pela mídia. Segundo o então prefeito, não havia documentos na prefeitura sobre o projeto e nem mesmo da associação de Palmas ao Iclei. O secretário de Meio Ambiente, empossado em 2005 na recém-criada Secretaria de Meio Ambiente e Turismo, corrobora a afirmação do então prefeito. Em entrevista, no ano de 2007, a um jornal local, o mesmo afirmou que, "quando assumimos a secretaria não havia nenhum registro de projeto tecnicamente construído para sequestro de carbono de floresta urbana e nem de conhecimento da comissão interministerial de Mudança Global do Clima” (Coelho, 2007). 
Entretanto, o então prefeito, quando indagado sobre as possíveis ações desenvolvidas no âmbito da Política Municipal de Mudanças Climáticas durante seus dois mandatos (200508 e 2009-12), afirmou que, devido ao próprio Protocolo de Kyoto não "ter avançado muito", a política municipal não teve um "dinamismo". Ainda segundo o então prefeito, "buscava-se dentro das normativas do tratado, agora as ações que o município tem desenvolvido eu penso que vão muito além do que foi estabelecido nessas metas". Ao afirmar que: "buscava-se dentro das normativas do tratado (Kyoto)", o então prefeito faz alusão ao projeto de sequestro de carbono. Entretanto, segundo ele, as ações que o município desenvolveu sob sua gestão são muito mais amplas e vão além de medidas de mitigação e redução das emissões de dióxido de carbono por meio do sequestro de carbono.

O então prefeito apontou várias ações de cunho ambiental, mas não diretamente ligadas à questão climática, em andamento em seu governo, ressaltando a importância da atuação do município na problemática. Entretanto, o diretor de Meio Ambiente da mesma gestão afirmou que ações foram implantadas no sentido de mitigação dos gases de efeito estufa amparadas pela Lei no 1.182 , e citou a Instrução Normativa de 2011, que prevê o plantio de árvores para a compensação de emissão de $\mathrm{CO}_{2}$ pelos organizadores dos eventos realizados na cidade. Além disso, o então prefeito ressaltou a falta de capacidade, técnica e financeira dos municípios para resolver o problema, fator previamente identificado na literatura sobre a governança urbana do clima.

Desta forma, a associação do município ao Iclei, o projeto de sequestro de carbono e a Política Municipal de Mudanças Climáticas aparecem na fala da maioria dos entrevistados como ações estratégicas de um mesmo projeto, o qual estava associado a um grupo político específico. No caso de Palmas, a não continuidade de sua participação no Iclei e, consequentemente, o não cumprimento de todas as etapas do Plano de Ação em grande medida estiveram relacionados com a descontinuidade política local.

A administração pública municipal (do período 2001-04) criou um sistema abrangente de gestão ambiental, que integrava diversas instituições e possuía um fundo próprio para financiar ações. Esses fatores demonstram o lugar de destaque que as questões ambientais ocupavam na agenda governamental do município. Essa perspectiva também é evidenciada nos depoimentos dos entrevistados, que estiveram envolvidos na gestão municipal à época, os quais mencionam que a presença da "vontade política" foi fundamental para que a cidade agisse em relação à proteção do clima. Além disso, o próprio perfil dos gestores da Amatur pode ser considerado um fator que influenciou, pois, além do presidente, os ocupantes dos cargos de confiança tinham proximidade com temas ambientais, com formações acadêmicas e trabalhos técnicos na área ambiental.

Por outro lado, não se pode avaliar se, caso a cidade continuasse participando da campanha CCP do Iclei, a implantação das políticas desenhadas em seu Plano de Ação seria possível, ou mesmo efetiva, devido às próprias dificuldades inerentes à implantação de medidas de mitigação pelos municípios. Além disso, a consecução de recursos financeiros via projeto de sequestro de carbono ainda necessitava de regulamentação, em que pese o fato de que não 
é função de uma agência reguladora como a Amatur "comercializar" bens públicos. Como era o primeiro projeto deste tipo no Brasil, as próprias barreiras legais-institucionais dificultariam a implementação desse projeto mesmo que houvesse vontade política nos gestores municipais de dar continuidade ao mesmo. No próprio texto do projeto constava que seria requerida ao governo brasileiro alguma forma de aprovação para transação de créditos de carbono pela Amatur (PSCUP, 2002).

Desta forma, a participação de Palmas no Iclei aparece ligada a um projeto político de determinado grupo, o que, aliado à falta de uma secretaria ou de uma diretoria de relações internacionais no município, acabou por contribuir para um distanciamento da possibilidade da atuação da cidade em redes transnacionais.

\section{Considerações finais}

Na investigação empreendida, confirmou-se a tendência já averiguada na literatura de que a participação em redes transnacionais influência a ação da administração pública municipal. Todavia, no caso de Palmas, essa influência, vivenciada por meio da participação na campanha CCP do Iclei, teve uma abrangência limitada. A motivação e a vontade política para a ação em mudanças climáticas já existiam antes mesmo da adesão ao Iclei, que era vista como uma oportunidade de captação de recursos para um projeto desenvolvido no âmbito da prefeitura. A primeira lei municipal de mudanças climáticas já havia sido pensada e todos esses fatores concorreram para que a cidade fosse aceita na campanha CCP. Neste sentido, a participação no Iclei não foi crucial para a formulação da política local, uma vez que uma Lei a este respeito já vinha sendo construída, mas colaborou de maneira indireta com a mesma.

Outra limitação observada foi a descontinuidade da participação na campanha CCP - provocada pela mudança de governo. Porém, não se pode afirmar que, caso a cidade de Palmas continuasse participando da campanha, a implantação das políticas desenhadas em seu plano de ação seria possível, ou mesmo efetiva, devido às próprias dificuldades inerentes à implementação de medidas desse tipo. Além disso, havia barreiras legais e institucionais para que o projeto de sequestro de carbono pudesse ser implementado e que se pudesse captar recursos financeiros por meio da comercialização de créditos de carbono no mecanismo MDL.

Um ponto em que a participação do Iclei foi importante refere-se à assessoria técnica proporcionada pela rede, por meio de treinamentos e disponibilização de um software, que foi decisivo para que a cidade mensurasse suas emissões e traçasse medidas a partir de um cenário fidedigno, levando-se em consideração que, ao contrário das grandes cidades brasileiras, não dispunha de recursos técnicos adequados. Além disso, a participação no Iclei foi importante para o reforço da capacidade local para poder agir sobre a problemática das mudanças climáticas, por meio da possibilidade de troca de experiências e capacitação técnica, proporcionadas pela rede. Entretanto, esse reforço de capacidades ficou "localizado" em uma conjuntura política da cidade, na medida em que os servidores municipais — ocupantes de 
cargos comissionados - e que atuavam na gestão das ações do município no âmbito da campanha se afastaram do quadro da administração pública municipal.

Percebe-se no caso analisado que as limitações encontradas se referem mais diretamente ao processo de ascensão do tema à agenda do governo local — ou seja, como a problemática das mudanças climáticas é percebida como um problema pelos gestores públicos, e, dessa forma, ascende à agenda governamental e se torna objeto de políticas - do que propriamente às dificuldades inerentes ao engajamento na rede. Na gestão 2001-04, a participação no Iclei era entendida como uma ação estratégica dentro de um projeto mais amplo e a possibilidade de captação de recursos financeiros foi um fator determinante para a motivação da adesão à rede.

Entretanto, com a descontinuidade política e não implementação do projeto de sequestro de carbono, a associação ao Iclei consequentemente deixou a agenda governamental, o que, aliado à falta de uma Secretaria ou de uma Diretoria de Relações Internacionais no município, que pudesse prospectar outras oportunidades de engajamento, acabou por contribuir para um distanciamento da possibilidade da atuação da cidade em redes transnacionais.

É patente a diferença das ameaças ambientais de cidades médias como Palmas e megacidades como São Paulo e Rio de Janeiro, por exemplo, o que talvez determine a fragilidade da permanência da problemática na agenda governamental por um longo período de tempo em detrimento de temas talvez considerados "mais urgentes", como saúde e educação. Da mesma forma, nesses municípios a questão dos recursos financeiros não é tão importante quanto nos municípios de menor porte como Palmas.

Desta forma, percebe-se a necessidade da realização de mais pesquisas para que se possa compreender como as cidades médias vêm efetuando esse tipo de engajamento e como ele pode trazer benefícios, principalmente ao se considerar a atual conjuntura de crise financeira e consequentes recursos escassos para financiamento de ações de cunho ambiental no mundo.

\section{Referências}

ABRUCIO, Fernando L. O impacto do modelo gerencial na administração pública: um breve estudo sobre a experiência internacional recente. Cadernos Enap, Brasília, n. 10, p. 6-44, 1996.

ANDONOVA, Liliana B.; BETSILL, Michele M.; BULKELEY, Harriet. Transnational Climate Change Governance. In: AMSTERDAM CONFERENCE ON THE HUMAN DIMENSIONS OF GLOBAL CLIMATE CHANGE, 24-26 May 2007, Amsterdã. Disponível em: <www.2007amsterdamconference. org/Downloads/AC2007_Betsill.pdf>. Acesso em: 2 jun. 2011.

BAZOLLI, João Aparecido. Os efeitos dos vazios urbanos no custo de urbanização da cidade de Palmas-TO. Estudos Geográficos, Rio Claro, v. 7, n. 1, p. 103-123, 2009.

BETSILL, Michele M. Mitigating climate change in US cities: opportunities and obstacles. Local Environment, v. 6, n. 4, p. 393-406, 2001. 
BETSILL, Michele M.; BULKELEY, Harriet. Cities and the multilevel governance of global climate change. Global Governance, v. 12, n. 2, p. 141-159, 2006.

BETSILL, Michele M.; BULKELEY, Harriet. Transnational networks and global environmental governance: the cities for climate protection program. International Studies Quarterly, v. 48, n. 2, p. 471-493, 2004.

BIDERMAN, Furriela R. Limites e alcances da participação pública na implementação de políticas subnacionais em mudanças climáticas e o município de São Paulo. Tese (doutorado) — Escola de Administração de Empresas de São Paulo, São Paulo, 2011.

BULKELEY, Harriet. Reconfiguring environmental governance: towards a politics of scales and networks. Political Geography, v. 24, n. 8, p. 875-902, 2005.

BULKELEY, Harriet; BETSILL, Michele M. Cities and climate change: urban sustainability and global environmental governance. Londres: Routledge, 2003.

BULKELEY, Harriet et al. Cities and climate change: the role of institutions, governance and urban planning. In: WORLD BANK 5TH URBAN SYMPOSIUM ON CLIMATE CHANGE, Marseille, 2009. Anais... p. 5-28.

CASTELLS, Manuel. Hacia el estado red? Globalización económica e instituciones políticas en la era da información. In: SEMINÁRIO INTERNACIONAL SOCIEDADE E A REFORMA DO ESTADO, São Paulo, 1998.

CNM. Confederação Nacional de Municípios. Diagnóstico da municipalização do meio ambiente no Brasil. out. 2009. Disponível em: <www.cnm.org.br/index.php?option=com_docman\&task=cat view\&gid=102\&Itemid=4>. Acesso em: 27 out. 2011 .

COELHO, Umberto S. Aquecimento global e mercado econológico incipiente no Tocantins. Jornal Conexão Tocantins, Palmas, 30 dez. 2007 (on-line). Disponível em: < http://conexaoto.com. br/2007/12/30/aquecimento-global-e-mercado-econologico-incipiente-no-tocantins > Acesso em: 3 jun. 2011.

DINIZ, Eli. Governabilidade, democracia e reforma do estado: os desafios da construção de uma nova ordem no Brasil dos anos 90. Dados - Revista de Ciências Sociais, Rio de Janeiro, v. 38, n. 3, p. 385-415, 1995.

EVANS, Bob et al. Governing sustainable cities. Londres: Earthscan, 2005.

FERREIRA, Leila C. A questão ambiental no Brasil: sustentabilidade e políticas públicas no Brasil. São Paulo: Boitempo, 2003.

FERREIRA, Leila C. La búsqueda de alternativas de sustentabilidad en el poder local. In: ZICCARDI, Alicia; LUJÁN, Sergio (Ed.). Ciudades Latinoamericanas. Modernizacion y Pobreza. Ciudad del México: Universidad Nacional Autónoma de México, 1999. p. 255-265.

GIDDENS, Anthony. The politics of climate change. Cambridge, UK: Polity Press, 2009.

HOGAN, Daniel J. Demographic aspects of global environmental change: what is Brazil's contribution? In: HOGAN, Daniel J.; TOLMASQUIM, Mauricio (Ed.). Human dimensions of global envi- 
ronmental change. Brazilian perspectives. Rio de Janeiro: Academia Brasileira de Ciências, 2001. p. 17-41.

IBGE. Instituto Brasileiro de Geografia e Estatística. Censo demográfico: Brasil. Rio de Janeiro: IBGE, 2010.

ICLEI. Cities for climate protection. an international campaign to reduce urban emissions of greenhouse gases. Written by Jeb Brugmann, Secretary General of ICLEI and Phillip Jessup, Director for the Urban CO2 Reduction Project, Toronto, 15 February 1993b.

ICLEI. Municipal leader's declaration on climate change and the urban environment. United Nations Headquarters, New York, 25-26 Jan. 1993a.

ICLEI. Who we are. Disponível em:<www.iclei.org/iclei-global/who-is-iclei.html>. Acesso em: 13 jun. 2013.

JACOBI, Pedro. Cidade e meio ambiente: percepções e práticas em São Paulo. 2. ed. São Paulo: Annablume, 2006.

JENSEN, Ole J. Networks as tools for sustainable urban development. In: INTERNATIONAL CONFERENCE INNOVATION, SUSTAINABILITY AND POLICY, Munich, Kloster Seeon, 2004.

KEINER, Marco; KIM, Arley. Transnational city networks for sustainability. European Planning Studies, v. 15, n. 10, p. 1369-1395, 2006.

KERN, Kristine; ALBER, Gotelind. Governing climate change in cities: modes of urban climate governance in multi-level systems. In: OECD INTERNATIONAL CONFERENCE, 2008, Milan.

KERN, Kristine; BULKELEY, Harriet. Cities, Europeanization and multi-level governance: governing climate change through transnational municipal networks. JCMS, Houston, Wiley Online Library, v. 47, n. 2, p. 309-332, 2009.

LANKAO, Patricia R. Are we missing the point? Particularities of urbanization, sustainability and carbon emissions in Latin American cities. Environment and Urbanization, v. 19, n. 1, p. 159-175, 2007a.

LANKAO, Patricia R. How do local governments in Mexico City manage global warming? Local Environment, v. 12, n. 5, p. 519-535, 2007b.

LINDSETH, Gard. The cities for climate protection campaign (CCPC) and the framing of local climate policy. Local Environment, v. 9, n. 4, p. 325-336, 2004.

LOIOLA, Elisabeth; MOURA, Suzana. Análise de redes: uma contribuição aos estudos organizacionais. In: FISCHER, T. (Org.). Gestão contemporânea, cidades estratégicas e organizações locais. Rio de Janeiro: FGV, 1997.

MARANDOLA JR., Eduardo (Org.). População e mudança climática: dimensões humanas das mudanças ambientais globais. Campinas: Ed. Unicamp, 2009.

MARTINS, Rafael A.; FERREIRA, Leila C. Oportunidades e barreiras para políticas locais e subnacionais de enfrentamento das mudanças climáticas em áreas urbanas: evidências de diferentes 
contextos. Ambiente e Sociedade, Campinas, v. 13, n. 2, p. 223-242, 2010. Disponível em: <www. scielo.br/pdf/asoc/v13n2/v13n2a02.pdf>. Acesso em: 3 jun. 2011.

MARTINS, Rafael A.; FERREIRA, Leila C. Uma revisão crítica sobre cidades e mudança climática: vinho velho em garrafa nova ou um novo paradigma de ação para a governança local? Rev. Adm. Pública, Rio de Janeiro, v. 45, n. 3, p. 611-642, maio/jun. 2011. Disponível em: <www.scielo. br/pdf/rap/v45n3/04.pdf>. Acesso em: 3 jun. 2011.

OJIMA, Ricardo. Perspectivas para adaptação frente às mudanças ambientais globais no contexto da urbanização brasileira: cenários para os estudos de população In: HOGAN, Daniel J.; MARANDOLA JR., Eduardo (Org.). População e mudança climática: dimensões humanas das mudanças ambientais globais. Campinas: Nepo/Unicamp, 2009. p. 11-24.

PALMAS (município). Lei no 1.011 de 04 de junho de 2001. Dispõe sobre a política ambiental, equilíbrio ecológico, preservação e recuperação do meio ambiente e dá outras providências.

PALMAS (município). Lei no 1.182 de 13 de maio de 2003. Institui a Política Municipal de Mudanças Climáticas e dá outras providências.

PALMAS (município). Lei no 1.365 de 05 março de 2005. Dispõe sobre a organização e estrutura administrativa do poder executivo do município de palmas e dá outras providências.

PARRY, Martin et al. (Ed.). Climate Change 2007: impacts, adaptation and vulnerability. Contribution of Working Group II to the Fourth Assessment Report of the IPCC. Cambridge: Cambridge University Press, 2007.

PEREIRA, Luiz C. B. Reflexões sobre a reforma gerencial brasileira. Revista do Serviço Público, Brasília, v. 50, n. 4, p. 5-29, 1999.

PSCUP. Projeto de Sequestro de Carbono Social Urbano. Palmas, 2002.

PUPPIM DE OLIVEIRA, José A. The implementation of climate change related policies at the subnational level: an analysis of three countries. Habitat International, v. 33, n. 3, p. 253-259, 2009.

RIBEIRO, Wagner C. Impactos das mudanças climáticas em cidades no Brasil. Parcerias Estratégicas, V. 27, p. 297-321, 2008.

ROBINSON, Pamela J.; GORE, Cristopher D. Barriers to Canadian municipal response to climate change. Canadian Journal of Urban Research, v. 14, n. 1, p. 102-120, 2005.

SANTOS, Maria Helena de C. Governabilidade, governança e democracia: criação de capacidade governativa e relações Executivo-Legislativo no Brasil pós-Constituinte. In: Dados [On-line], Rio de Janeiro, v. 40, n. 3, 1997. Disponível em: <www.scielo.br/scielo.php?script=sci_arttext\&pid=S001152581997000300003 >. Acesso em: 7 jun. 2013.

SATTERTHWAITE, David et al. Building climate resilience in urban areas among urban populations in low-and middle-income countries. Londres: Center for Sustainable Urban Development, 2007.

SATTERTHWAITE, David et al. Climate change and urbanization: effects and implications for urban governance. Nova York: United Nations Expert Group Meeting on Population Distribution, Urbanization, Internal Migration and Development, UN/POP/EGMURB/2008/16, 2008. 
SCARDUA, Fernando; BURSZTYN, Maria Augusta. Descentralização da política ambiental no Brasil. Sociedade e Estado, Brasília, v. 18, n. 1-2, p. 291-314, 2003. Disponível em: <www.scielo.br/pdf/ se/v18n1-2/v18n1a13.pdf>. Acesso em: 7 jun. 2013.

SETZER, Joana. Subnational and transnational climate change governance: evidence from the state and city of São Paulo, Brazil. In: WORLD BANK 5TH URBAN SYMPOSIUM ON CLIMATE CHANGE, 2009, Marseille.

WILBANKS, Thomas J. et al. Industry, settlement and society. In: PARRY, M. et al. (Ed.). Climate change 2007: impacts, adaptation and vulnerability. Contribution of Working Group II to the Fourth Assessment Report of the Intergovernmental Panel on Climate Change. Cambridge: Cambridge University Press, 2007. p. 357-390.

WILBANKS, Thomas J.; KATES, Robert W. Global change in local places: how scales matters. Climate Change, v. 43, n. 3, p. 601-628, 1999.

Lia de Azevedo Almeida é doutoranda em administração pública pelo Programa de Pós-Graduação em Administração da Universidade de Brasília (PPGA/UnB) e professora da Universidade Federal do Tocantins (UFT).E-mail: lia.almeida@uft.edu.br.

Mônica Aparecida da Rocha Silva é doutora em ciências sociais pela Universidade de Brasília (UnB) e professora do Mestrado em Desenvolvimento Regional da Universidade Federal do Tocantins (UFT). E-mail: monicars@uft.edu.br.

Ronaldo Augusto Campos Pessoa é doutor em Sociologia/Verwaltungswissenschaft pela Universität Speyer/Freie Universität Berlin (US/FUB) e professor da Universidade Federal do Tocantins (UFT). Email: camposbr@hotmail.com. 
